\title{
Análise bibliográfica da produção em saúde sobre adolescentes cumprindo medidas socioeducativas de privação de liberdade
}

\section{| ${ }^{1}$ Nilo Terra Arêas Neto, ${ }^{2}$ Patrícia Constantino, ${ }^{3}$ Simone Gonçalves de Assis |}

Resumo: Este estudo teve por função analisar a publicação de artigos científicos da área da saúde sobre adolescentes cumprindo medidas socioeducativas de privação de liberdade no Estado do Rio de Janeiro, Brasil. Realizouse revisão sistemática integrativa nas bases de dados entre os anos de 2000 e 2015: Scopus (67 artigos), Scielo (73 artigos), Portal BVS (50 artigos) e Pubmed/Medline (13 artigos), totalizando 218 documentos. Após descartes por duplicação e não preenchimento dos critérios de inclusão, permaneceram no acervo 42 documentos, que foram analisados. Foi realizada categorização temática: caracterização do adolescente em conflito com a lei (15 documentos); conceitos, legislação e histórico das medidas socioeducativas e ações institucionais para adolescentes privados de liberdade (8); saúde (9); representação social do adolescente em conflito com a lei (5); e relação familiar (5).Um total de $57,1 \%$ dos artigos foram publicados entre 2010 e 2015, especialmente em periódicos de psicologia e saúde pública, em sua maioria com metodologia qualitativa e publicados por pesquisadores das regiôes Sudeste e Sul do Brasil. Após análise dos resultados, constatou-se uma maior ênfase aos trabalhos sobre a saúde mental da população estudada em contraponto a uma escassez quase total de estudos sobre a saúde física. Também se pode observar na literatura especializada que a precária assistência e a promoção da saúde do adolescente privado de liberdade constituem desafios complexos e multifatoriais, seja pela dificuldade de articulação da rede de saúde no atendimento ao adolescente institucionalizado, seja pela persistência da lógica punitiva nos estabelecimentos destinados à socioeducação.

> Palavras-chave: saúde; adolescentes; privação de liberdade.
${ }^{1}$ CLAVES, Escola Nacional de Saúde Pública Sergio Arouca, Fundação Oswaldo Cruz. Rio de Janeiro-RJ, Brasil (terra. nilo@gmail.com).

${ }^{2}$ CLAVES, Escola Nacional de Saúde Pública Sergio Arouca, Fundação Oswaldo Cruz. Rio de Janeiro-RJ, Brasil (paticons@claves.fiocruz.br).

${ }^{3}$ CLAVES, Escola Nacional de Saúde Pública Sergio Arouca, Fundação Oswaldo Cruz. Rio de Janeiro-RJ, Brasil (simone@claves.fiocruz.br). 
Apesar de a violência urbana possuir um caráter multifatorial, um aspecto muito destacado pela sociedade é a associação entre juventude e criminalidade. Simultaneamente vítimas e agentes de diferentes formas de violência, os adolescentes em conflito com a lei e privados de liberdade estão entre os mais afetados e vivem as contradições e dimensões de exclusão na sociedade (COELHO, 2013).

Zappe e Ramos (2010) destacam que a autoria dos atos infracionais chama muito mais a atenção da mídia e da sociedade em geral que a vitimização a que estão submetidos e que também é decorrente da precariedade de políticas públicas efetivas nos âmbitos da escolarização e profissionalização de crianças e adolescentes brasileiros.

Os altos índices de envolvimento de adolescentes em conflito com a lei não são exclusividades do Brasil. Esse fenômeno, que em casos mais graves acaba levando a medidas de restrição e privação da liberdade, é observado em diversos países do mundo (ASSIS; CONSTANTINO, 2005).

Entre as medidas socioeducativas previstas no Estatuto da Criança e do Adolescente (BRASIL, 1990), a internação é a mais severa e restritiva, afastando os adolescentes do ambiente familiar, escolar e comunitário em que vivem e institucionalizando-os junto a pares, também autores de infrações. A legislação afirma que essas medidas devem ser aplicadas preservando-se o princípio da brevidade e da excepcionalidade, a fim de se respeitar a condição peculiar de pessoa em desenvolvimento. A privação de liberdade prevista em lei tem o objetivo de concretizar o princípio de reparação do ato cometido, numa lógica oposta à de castigo (BRASIL, 2012a).

Apesar desta perspectiva dos documentos oficiais descrita acima, estudos empíricos realizados também por organismos oficiais reforçam a contradição entre o ideário jurídico e a realidade de nossas instituições. Em relatório apresentado na Assembleia Legislativa do Rio de Janeiro relativo ao ano de 2015, ficou demonstrado que os espaços de internação no país são favoráveis à prática de tortura, tratamentos cruéis, desumanos e degradantes (BRASIL, 2013; RIO DE JANEIRO, 2015).

Apesar do Censo Demográfico de 2010 do IBGE demonstrar que os adolescentes cumprindo medidas de privação de liberdade no Brasil representam cerca de $1 \%$ do total de adolescentes no país, o Levantamento Nacional sobre o 

2011), divulgado pela Secretaria dos Direitos Humanos da Presidência da República, informava, em 2011, que 12 estados brasileiros tiveram expressivo aumento no número de adolescentes que estavam cumprindo medidas socioeducativas de internação. O mesmo levantamento, realizado a seguir (BRASIL, 2013), encontrou 23.066 pessoas com idade entre 12 e 21 anos cumprindo medidas socioeducativas no país. Desses, 22.683 eram do sexo masculino e 1.042, do feminino; 5.573 estavam em internação provisória, 2.272 em semiliberdade e 15.221 em privação de liberdade - o que corresponde a 67,1\% do total de adolescentes apreendidos, contrariando a noção de excepcionalidade. Do total de adolescentes em privação de liberdade, 15,6\% cumpriam medidas socioeducativas por prática de ato infracional contra a vida. Tão grave quanto esses números é constatar que a maioria desses adolescentes podia cumprir medida socioeducativa alternativa à internação, pois não são reincidentes nem praticaram ato infracional de maior potencial ofensivo.

As unidades de atendimento socioeducativo e as medidas socioeducativas, originalmente concebidas como estratégias de reinserção social, apontam mais para as fragilidades do que para o êxito de seus propósitos. As condições de aplicação das medidas socioeducativas de internação muitas vezes desrespeitam direitos humanos básicos, descaracterizam seus propósitos e intensificam processos de exclusão, comprometendo as condições de saúde e de desenvolvimento do adolescente (DAVOGLIO et al., 2011; BRASIL, 2012a; COELHO, 2013; RIO DE JANEIRO, 2015). Visando enfrentar a precariedade institucional existente, foi concebida a Lei 5.778, de 2010, que criou no Estado do Rio o Mecanismo Estadual de Prevenção e Combate à Tortura (MEPCT), que determina que uma comissão composta por especialistas, com mandatos temporalmente delimitados e com atuação autônoma, atue planejando e realizando visitas periódicas e regulares a espaços de privação de liberdade, com o propósito de se identificar rotinas e padrões que indiquem a ocorrência da tortura, produzindo relatórios com os resultados das visitas.

O mesmo Relatório de 2015 supracitado (RIO DE JANEIRO, 2015) demonstrou que a lógica da socioeducação no Estado do Rio de Janeiro é ofuscada pela lógica punitiva, militarizada, disciplinadora, que utiliza métodos como uso de spray de pimenta, eletrochoque, medidas de isolamento e relatos de agressões 
físicas e verbais. Castro e Guareschi (2008, p. 206) afirmam ser "premente uma política nacional que oriente e fiscalize a aplicação das medidas socioeducativas, pondo fim, em definitivo, às verdadeiras prisões juvenis que grassam no país".

A legislação brasileira ressalta que os direitos de assistência e cuidados destinados às crianças e adolescentes são extensivos a todos, inclusive àqueles privados de liberdade. Segundo o ECA (BRASIL, 1990), esses adolescentes estão privados de sua liberdade e não dos seus direitos, e deveriam ter prioridade na implementação de políticas sociais básicas, além de um conjunto de ações corretivas, preventivas e inclusivas (BRASIL, 1990; BRASIL, 2012a).

Os cuidados prestados à saúde no contexto de privação de liberdade ocupam plano secundário, assim como ocorre com as ações de promoção à saúde, sendo ambas essenciais para integrar o adolescente ao contexto social e para promover fatores de proteção e reduzir riscos (COSTA, 2007). Nesse sentido, o caráter reparador da aplicação de medida socioeducativa necessita estar associado ao cuidado e à promoção da saúde e da qualidade de vida, já que esta é vista como a modalidade mais completa de prevenção ao ato infracional, segundo o ECA (BRASIL, 1990).

O principal objetivo desta investigação foi conhecer e analisar a produção bibliográfica na área da saúde sobre adolescentes, cumprindo medidas socioeducativas de privação de liberdade no Brasil, tendo como questão norteadora quais os aspectos abordados nas publicações científicas brasileiras da área sobre a saúde desses adolescentes.

Importante destacar que o sujeito-adolescente investigado encaixa-se em uma dupla situação de exceção, do ponto de vista biopsicossocial e jurídico: é um adolescente que vivencia o período conturbado dessa fase do desenvolvimento, caracterizada por rebeldias, contradiçōes e ambivalências; além disso, tem seu conflito estendido para além de si mesmo e de seu meio social, pois está em conflito também com a lei (JOST, 2010; RIO DE JANEIRO, 2015).

\section{Métodos}

Foi realizada revisão sistemática integrativa de literatura na área da saúde, identificando, selecionando e avaliando criticamente investigações consideradas relevantes, no intuito de dar suporte teórico-prático para a classificação e análise da pesquisa bibliográfica (LIBERALI, 2011). A análise integrativa tem ampla 
abrangência, permitindo incluir distintos tipos de métodos de estudos, bem como perspectivas teóricas e empíricas. Parte de uma questão específica, da exposição do processo de busca do acervo estudado na literatura científica, da categorização, avaliação e interpretação dos estudos, culminando com a síntese dos resultados e apresentação da revisão, proposta concretizada neste artigo (MENDES et al., 2008).

Como fontes de informação da literatura científica, utilizaram-se as seguintes bases de dados entre os anos de 2000 e 2015: Scientific Eletronic Library Online - Scielo (73 artigos); Biblioteca Virtual em Saúde - Portal BVS (50 artigos) e Medical Literature Analysis and Retrieval System Online - Pubmed/Medline (13 artigos); Scopus (67 artigos); e Web of Science (15 artigos). Os resultados foram filtrados para área da saúde. Obteve-se um total de 218 registros; foram excluídos 73 textos por duplicidade, alcançando-se 145 documentos distintos, que foram lidos a partir dos títulos, resumos e palavras-chave para avaliar a adequação ao objeto de estudo. Nesta etapa, 103 documentos foram eliminados, após a adoção dos critérios de inclusão e exclusão mencionados adiante. No total, 42 textos são analisados no presente artigo

Foram utilizados os seguintes descritores em português e inglês, no singular e no plural, para a seleção do acervo analisado: adolescentes, juventude, jovem infrator, menor infrator, jovem em conflito com a lei, delinquência juvenil, comportamento desviante, adolescente em conflito com a lei, medidas de restrição de liberdade, medida socioeducativa, medida de internação, privação de liberdade, medida socioeducativa restritiva, ato infracional, menor infrator.

Os critérios que balizaram a seleção dos 42 estudos nacionais são os seguintes: 1) de inclusão: artigos em português, inglês e espanhol sobre adolescentes privados de liberdade, publicados entre 2000 e 2015, sem restrição quanto ao desenho metodológico, desde que contendo os descritores mencionados. No caso dos artigos empíricos, os dados apresentados referem-se ao Brasil; para os teórico-conceituais não há esta restrição; 2) de exclusão: periódicos de outras áreas que não a da saúde (educação, serviço social, direito e antropologia); no caso de estudos empíricos, com dados de outros países que não o Brasil; textos sem relação com a população da pesquisa (muitos deles eram sobre adultos em situação de aprisionamento); e sobre outras medidas socioeducativas que não a privação de liberdade. 
Todos os 42 artigos analisados no artigo foram obtidos em sua versão integral e lidos, para se efetuar a categorização e análise apresentada a seguir (com exceção de OLIVEIRA et al., 2015, que não foi obtido na íntegra). A seleção dos artigos foi feita por dois pesquisadores, de forma independente, e discrepâncias existentes foram decididas em conjunto pelos pesquisadores. Os eixos temáticos obtidos na análise são: conceitos, legislação e histórico das medidas socioeducativas e atuação institucional (8 artigos); caracterização do adolescente em conflito com a lei (17); saúde (8); representação social do adolescente em conflito com a lei (4); e relação familiar (5). Documentos com interesses temáticos variados foram incluídos em apenas um eixo, considerado predominante.

\section{Resultados}

A maior parte da produção científica incluída neste estudo se deu no período mais recente (2010 a 2015), com 24 dos 42 artigos publicados, coincidindo com a intensificação das internaçõos decorrentes das infraçōes cometidas por adolescentes nos últimos anos, expressa nas estatísticas oficiais brasileiras.

Em relação às áreas de publicação dos periódicos, a psicologia predominou, com 17 dos 42 artigos. Em sequência, estão: saúde coletiva/pública (9), multidisciplinar (7), psiquiatria (6), saúde bucal (2), educação física (1). A utilização de pesquisa qualitativa predominou (23 artigos), seguida pela triangulação metodológica quali-quantitativa (10), pelos estudos quantitativos (6) e os conceituais ou de revisão (3).

A região Sudeste tem maior participação nos estudos publicados, com 18 dos 42 artigos incluídos na análise, seguida pela Sul (13). Nordeste e Centro-Oeste contribuíram com quatro artigos cada e o Norte, com duas publicaçôes. Esta análise foi realizada segundo a localização da instituição de origem dos autores. Um dos artigos não possuía identificação de origem. Três dessas publicações foram produzidas em parceria com instituições internacionais (HUCULAK et al., 2011; MCLENNAN et al., 2008; PERES et al., 2002).

\section{Conceitos, legislação e histórico das medidas socioeducativas e ações institucionais para adolescentes privados de liberdade}

Neste variado grupo incluem-se 8 artigos com conceitos e legislações relativas ao atendimento socioeducativo no Brasil, que abordam o histórico do cumprimento 
das medidas socioeducativas de internação no país, além de documentos que relatem ações institucionais no ambiente socioeducativo (quadro 1). A maioria encontra-se em periódicos da área da saúde (6) e aborda a dificuldade em se substituir o modelo arcaico, punitivo e coercitivo por uma lógica socializadora, proposta na Doutrina de Proteção Integral da Infância e da Juventude, das Nações Unidas, e contemplada em legislações específicas como o ECA, o Sistema Nacional de Atendimento Sócio Educativo (BRASIL, 2012a) e a Política Nacional de Atenção Integral à Saúde de Adolescentes em Conflito com a Lei em Regime de Internação e Internação Provisória (BRASIL, 2012b), tanto na apreciação dos processos quanto no atendimento socioeducativo (SCISLESKI et al., 2014; CIARALLO; ALMEIDA, 2009; SILVA; RISTUM, 2010; FEITOSA; BOARINI, 2014; VICENTIN, 2011; GURALH, 2012).

Quadro 1. Artigos sobre conceitos, legislação e histórico das medidas socioeducativas e açôes institucionais envolvendo adolescentes com medidas de internação ( $N=8)$

\begin{tabular}{|l|l|l|}
\hline \multicolumn{1}{|c|}{$\begin{array}{c}\text { Autor e } \\
\text { referência }\end{array}$} & \multicolumn{1}{|c|}{ Objetivo } & \multicolumn{1}{c|}{ Resultados } \\
\hline $\begin{array}{l}\text { SCISLESKI } \\
\text { et al., 2014 }\end{array}$ & $\begin{array}{l}\text { Problematizar os modos pelos } \\
\text { quais a tecnologia disciplinar, } \\
\text { presente nas medidas } \\
\text { socioeducativas de internação, } \\
\text { vem sendo operacionalizada. }\end{array}$ & $\begin{array}{l}\text { A tecnologia disciplinar que vem sendo } \\
\text { utilizada assemelha-se a um dispositivo de } \\
\text { controle com o objetivo de docilizar. Trata } \\
\text { de um corpo biológico que sofre efeitos } \\
\text { de uma ação, em vez de um método } \\
\text { socioeducativo. }\end{array}$ \\
\hline $\begin{array}{l}\text { FEITOSA \& } \\
\text { BOARINI, }\end{array}$ & $\begin{array}{l}\text { Avaliar a existência de aspectos } \\
\text { do higienismo nas justificativas } \\
\text { das sentenças judiciais. }\end{array}$ & $\begin{array}{l}\text { Continua-se, por determinação judicial, } \\
\text { a retirar o adolescente da situação de } \\
\text { delinquência e, encerrado o prazo judicial, } \\
\text { devolvê-lo para o mesmo contexto. } \\
\text { Aspectos do ideário da higiene mental e } \\
\text { da doutrina menorista são mantidos. }\end{array}$ \\
\hline $\begin{array}{l}\text { GURALH, } \\
2012\end{array}$ & $\begin{array}{l}\text { Relacionar os elementos } \\
\text { assentados constitucionalmente } \\
\text { no que tange à liberdade inscrita } \\
\text { como direito fundamental } \\
\text { aos elementos colocados pelo } \\
\text { ECA, ao tratar da privação de } \\
\text { liberdade. }\end{array}$ & $\begin{array}{l}\text { Número de internaçáes no país demonstra } \\
\text { que os operadores do Sistema de Garantias } \\
\text { da Criança e do Adolescente estão } \\
\text { atuando na contramão dos princípios } \\
\text { buscados pela legislação específica. O } \\
\text { paradigma colocado pela Doutrina da } \\
\text { Proteção Integral não obtém êxito no } \\
\text { rompimento e superação das práticas } \\
\text { repressivas e penalizadoras. }\end{array}$ \\
\hline
\end{tabular}




\begin{tabular}{|c|c|c|}
\hline $\begin{array}{l}\text { Autor e } \\
\text { referência }\end{array}$ & Objetivo & Resultados \\
\hline $\begin{array}{l}\text { VICENTIN, } \\
2011\end{array}$ & $\begin{array}{l}\text { Trabalhar conceitualmente } \\
\text { as experiências de sofrimento } \\
\text { vividas por adolescentes no } \\
\text { cumprimento de medida de } \\
\text { internação. }\end{array}$ & $\begin{array}{l}\text { Necessidade de (re) politizar a violência } \\
\text { exercida e padecida pelos adolescentes } \\
\text { como forma de desnaturalizar a violência } \\
\text { juvenil. }\end{array}$ \\
\hline $\begin{array}{l}\text { MALVASI, } \\
2011\end{array}$ & $\begin{array}{l}\text { Analisar a natureza social } \\
\text { e política do sofrimento de } \\
\text { um adolescente durante o } \\
\text { cumprimento de medidas } \\
\text { socioeducativas. }\end{array}$ & $\begin{array}{l}\text { O cumprimento de medida de internação } \\
\text { reforça a aflição de ser socialmente tido } \\
\text { como suspeito e fugitivo e a incorporação } \\
\text { de um lugar social particular, o de } \\
\text { membro do "mundo do crime". }\end{array}$ \\
\hline $\begin{array}{l}\text { COSTA et al., } \\
2011\end{array}$ & $\begin{array}{l}\text { Informar sobre os resultados } \\
\text { obtidos em uma intervenção } \\
\text { artística com adolescentes } \\
\text { internos do Estado do Amazonas. }\end{array}$ & $\begin{array}{l}\text { A arte revela-se instrumento útil } \\
\text { para o autoconhecimento, para o } \\
\text { desenvolvimento da percepção e do senso } \\
\text { estético, para a estimular a criatividade } \\
\text { e para melhorar o convívio social no } \\
\text { ambiente socioeducativo. }\end{array}$ \\
\hline $\begin{array}{l}\text { SILVA \& } \\
\text { RISTUM, } \\
2010\end{array}$ & $\begin{array}{l}\text { Compreender a percepção dos } \\
\text { professores e as especificidades } \\
\text { das relações de ensino- } \\
\text { aprendizagem em uma } \\
\text { escola inserida no sistema } \\
\text { socioeducativo. }\end{array}$ & $\begin{array}{l}\text { As manifestações de violência se dão, } \\
\text { em grande parte, de formas sutis, e } \\
\text { são percebidas como capazes de afetar } \\
\text { diretamente a atuação dos professores em } \\
\text { sala de aula. }\end{array}$ \\
\hline $\begin{array}{l}\text { CIARALLO } \\
\& \\
\text { ALMEIDA, } \\
2009\end{array}$ & $\begin{array}{l}\text { Conhecer como o adolescente é } \\
\text { retratado nos processos judiciais, } \\
\text { na apuração de atos infracionais. }\end{array}$ & $\begin{array}{l}\text { Representações compartilhadas na Justiça } \\
\text { são ancoradas em modelo tutelar, em que } \\
\text { o adolescente é objeto de direito, cujo } \\
\text { futuro, na condição de infrator, deve ser } \\
\text { traçado pelo Estado. }\end{array}$ \\
\hline
\end{tabular}

Vicentin (2011) aborda em seu texto a noção de sofrimento experimentado pelos adolescentes institucionalizados, especialmente quando colocados numa espécie de zona intermediária entre a vida e a morte, quando o sofrimento torna-se ato político numa espécie de rebelião de si. Malvasi (2011), abordando o histórico da execução das medidas socioeducativas, analisa a natureza sociopolítica do sofrimento no cumprimento de medida socioeducativa pelos adolescentes internos. Também investiga o conceito de "sofrimento social", relacionando-o à compreensão das situações de aflição e dor como experiências sociais e não como problemas individuais. 
Já Costa et al. (2011) informam que as atividades socioeducativas artísticas realizadas com adolescentes internos contribuíram para o estabelecimento de metas e projetos de vida, favoreceram a mitigação do "sofrimento", facilitando a expressão de suas subjetividades e colaborando para interações mais saudáveis entre internos e funcionários da unidade socioeducativa. A visão das dificuldades desses adolescentes na escola e no sistema judicial está presente nos trabalhos de Silva e Ristum (2010) e Ciarallo e Almeida (2009), respectivamente.

\section{Caracterização dos Adolescentes Internos no Sistema Socioeducativo}

Categoria com 17 artigos (QUADRO 2), que destaca: perfil sociodemográfico, infração cometida, histórico de violência e drogadição. Três desses documentos foram produzidos em parceria com universidades do Canadá (2) e Estados Unidos (1) (HUCULAK et al., 2011; MCLENNAN et al., 2008; PERES et al., 2002).

Seis textos diferenciaram o sexo na análise de seus resultados (PERES et al., 2002; MATTAR, 2008; SENA; COLARES, 2008; HUCULAK et al., 2011; BASTOS; MARIN, 2014; PRIULI; MORAES, 2007). Bastos e Marin (2014, p. 176) afirmam que as adolescentes do sexo feminino são mais difíceis no trato diário, e que "os estudos sobre a adolescente em conflito com a lei ainda são escassos, o que reflete sua invisibilidade social. Contudo, as pesquisas sobre as questôes que atravessam o tema 'criminalidade feminina' são ainda mais raras". Já Mattar (2008) destaca que, apesar de ser reconhecida como meio de fortalecer os vínculos familiares e diminuir a promiscuidade nas instituições, as visitas íntimas são oferecidas apenas aos meninos. Meninas não têm o direito à sexualidade respeitado. Apesar de o número de meninas privadas de liberdade ser esmagadoramente menor que o de meninos, aspectos morais relacionados à não aceitação socioinstitucional da sexualidade feminina podem estar contribuindo decisivamente para a desigualdade no tratamento. 

Socioeducativo em medida de internação $(\mathrm{N}=15)$

\begin{tabular}{|c|c|c|}
\hline Autor e ano & Objetivo & Resultados \\
\hline $\begin{array}{l}\text { BASTOS \& } \\
\text { MARIN, } 2014\end{array}$ & $\begin{array}{l}\text { Refletir sobre adolescentes } \\
\text { autoras de ato infracional, } \\
\text { tendo como ponto de partida } \\
\text { a fala da instituição, que } \\
\text { nomeia mais difícil o trabalho } \\
\text { com o sexo feminino. }\end{array}$ & $\begin{array}{l}\text { Ocorreram atos de exibição obscena } \\
\text { e exposição do corpo nu por parte } \\
\text { das adolescentes para as educadoras. } \\
\text { Considerando o lugar que o corpo ocupa na } \\
\text { estruturação psíquica do sujeito, e } \\
\text { especialmente as diferenças anatômicas entre } \\
\text { os sexos, é adequado pensar que a natureza } \\
\text { das angústias e os conflitos do sexo feminino } \\
\text { seriam necessariamente diferentes } \\
\text { dos do sexo masculino. }\end{array}$ \\
\hline $\begin{array}{l}\text { ZAPPE, \& } \\
\text { DIAS, 2012a }\end{array}$ & $\begin{array}{l}\text { Abordar as relações entre } \\
\text { adolescência, violência e uso } \\
\text { de drogas entre adolescentes } \\
\text { autores de ato infracional. }\end{array}$ & $\begin{array}{l}\text { A associação entre adolescência, violência e } \\
\text { uso de drogas foi identificada em todos os } \\
\text { casos. }\end{array}$ \\
\hline $\begin{array}{l}\text { HUCULAK, } \\
\text { MCLENNAN } \\
\& \text { BORDIN, } \\
2011\end{array}$ & $\begin{array}{l}\text { Determinar a extensão da } \\
\text { exposição à violência na } \\
\text { comunidade entre jovens } \\
\text { brasileiros delinquentes e } \\
\text { identificar fatores associados a } \\
\text { essa exposição. }\end{array}$ & $\begin{array}{l}325 \text { adolescentes internados ( } 89 \% \text { meninos) } \\
\text { referiram altas taxas de exposição à } \\
\text { violência: sofrido ameaças de lesão física, } \\
\text { sido espancado ou assaltado e/ou baleado } \\
\text { foram mais comuns. O relacionamento } \\
\text { com jovens envolvidos em comportamentos } \\
\text { de risco, o fácil acesso a armas de fogo e a } \\
\text { passagem prévia pela Justiça associaram-se à } \\
\text { violência testemunhada; ter dormido na rua } \\
\text { associou-se à violência vivenciada. }\end{array}$ \\
\hline $\begin{array}{l}\text { ZAPPE \& } \\
\text { RAMOS, } \\
2010\end{array}$ & $\begin{array}{l}\text { Construir o perfil dos } \\
\text { adolescentes em Centro } \\
\text { Socioeducativo. }\end{array}$ & $\begin{array}{l}\text { Adolescentes vivem dilema ao buscar } \\
\text { reconhecimento social numa sociedade em } \\
\text { que as principais modalidades de inserção } \\
\text { estão distantes ou mesmo inacessíveis, em } \\
\text { função das desigualdades sociais. }\end{array}$ \\
\hline JOST, 2010 & $\begin{array}{l}\text { Avaliar as motivações } \\
\text { mobilizadoras do perfil } \\
\text { de comportamento do } \\
\text { adolescente em conflito com } \\
\text { a lei, adotando o conceito } \\
\text { interativo do ato infracional. }\end{array}$ & $\begin{array}{l}\text { Os resultados revelaram uma ambivalência } \\
\text { vivencial que corrompe as subjetividades } \\
\text { e fragmenta os relacionamentos } \\
\text { intersubjetivos, forjando angústia } \\
\text { existencial, que se expressa em ações contra } \\
\text { si mesmo e a sociedade. }\end{array}$ \\
\hline
\end{tabular}

continua... 


\begin{tabular}{|c|c|c|}
\hline Autor e ano & Objetivo & Resultados \\
\hline $\begin{array}{l}\text { KOBAYASHI } \\
\& \text { ZANE, } \\
2010\end{array}$ & $\begin{array}{l}\text { Identificar a fase do } \\
\text { desenvolvimento moral dos } \\
\text { adolescentes. }\end{array}$ & $\begin{array}{l}\text { Características de moral heteronômica, } \\
\text { verificadas pelas diferenças entre a } \\
\text { consciência e a prática de regras na situação } \\
\text { de jogo. Apesar de conhecerem as regras, } \\
\text { durante a partida, somente as respeitam para } \\
\text { obterem benefícios. }\end{array}$ \\
\hline $\begin{array}{l}\text { MATTAR, } \\
2008\end{array}$ & $\begin{array}{l}\text { Conhecer como se dá o } \\
\text { exercício da sexualidade pelos } \\
\text { adolescentes. }\end{array}$ & $\begin{array}{l}\text { Pouco interesse na forma em que é exercida } \\
\text { a sexualidade por adolescentes privados de } \\
\text { liberdade. Pouca atenção é dada a quase } \\
\text { todos os aspectos da vida dos adolescentes. } \\
\text { Informa "existir uma negação da vida sexual } \\
\text { dos adolescentes na maioria dos centros de } \\
\text { internação do país". }\end{array}$ \\
\hline $\begin{array}{l}\text { MARTINS } \\
\& \text { PILLON, } \\
2008\end{array}$ & $\begin{array}{l}\text { Analisar a possível relação } \\
\text { entre a primeira experiência } \\
\text { do uso de drogas e o primeiro } \\
\text { ato infracional. }\end{array}$ & $\begin{array}{l}\text { Índices do primeiro uso do álcool, } \\
\text { cigarro e maconha são elevados e ocorrem } \\
\text { concomitantemente. Idade média de } 12 \\
\text { anos. Delitos mais praticados: roubo, tráfico } \\
\text { de drogas e furto. Correlação significativa } \\
\text { entre uso do álcool e maconha com os atos } \\
\text { infracionais, exceto o homicídio. }\end{array}$ \\
\hline $\begin{array}{l}\text { SENA \& } \\
\text { COLARES, } \\
2008\end{array}$ & $\begin{array}{l}\text { Investigar as condutas de } \\
\text { saúde entre adolescentes. }\end{array}$ & $\begin{array}{l}\text { Entre os } 241 \text { adolescentes, } 79,7 \% \text { portaram } \\
\text { arma; } 52,7 \% \text { se envolveram em briga com } \\
\text { agressão física nos últimos } 12 \text { meses. Muitos } \\
\text { eram usuários de tabaco }(87,6 \%) \text {, álcool } \\
(64,7 \%) \text {, e já experimentaram produtos } \\
\text { inalantes }(68,9 \%) \text { e maconha }(81,3 \%) \text {. A } \\
\text { maioria dos adolescentes }(95,4 \%) \text { tinha } \\
\text { tido relação sexual, em geral com mais } \\
\text { de um parceiro. Apresentaram vários } \\
\text { comportamentos de risco à saúde. }\end{array}$ \\
\hline $\begin{array}{l}\text { MCLENNAN } \\
\text { et al., } 2008\end{array}$ & $\begin{array}{l}\text { Descrever o comportamento } \\
\text { delinquente juvenil no } \\
\text { tráfico de drogas e identificar } \\
\text { experiências adversas como } \\
\text { potencial preditor de tráfico. }\end{array}$ & $\begin{array}{l}\text { Aproximadamente metade dos } 325 \text { meninos } \\
\text { e meninas afirmam ter tido algum papel no } \\
\text { tráfico de drogas antes do encarceramento. }\end{array}$ \\
\hline $\begin{array}{l}\text { PRIULI \& } \\
\text { MORAES, } \\
2007\end{array}$ & $\begin{array}{l}\text { Levantar o perfil } \\
\text { sociodemográfico, infracional } \\
\text { e relacional de adolescentes. }\end{array}$ & $\begin{array}{l}\text { Entre os } 48 \text { adolescentes, } 68,7 \% \text { possuíam } \\
\text { o ensino fundamental incompleto e } 83,3 \% \\
\text { não frequentavam a escola. Grande parte } \\
\text { não realizava trabalho remunerado por } \\
\text { ocasião da apreensão }(72,9 \%) \text {. }\end{array}$ \\
\hline
\end{tabular}

continua.. 


\begin{tabular}{|c|c|c|}
\hline Autor e ano & Objetivo & Resultados \\
\hline $\begin{array}{l}\text { PINHO et al., } \\
2006\end{array}$ & $\begin{array}{l}\text { Descrever o perfil } \\
\text { psiquiátrico, destacando os } \\
\text { transtornos em comorbidade } \\
\text { entre os adolescentes da Casa } \\
\text { de Acolhimento ao Menor } \\
\text { (CAM). }\end{array}$ & $\begin{array}{l}\text { Dos } 290 \text { indivíduos, } 89,3 \% \text { do sexo } \\
\text { masculino; } 63,9 \% \text { entre } 15 \text { e } 18 \text { anos } \\
\text { incompletos; } 95,1 \% \text { com ensino } \\
\text { fundamental incompleto ou analfabeto; } \\
67,6 \% \text { com renda familiar menor que um } \\
\text { salário mínimo; } 75,2 \% \text { com critérios para } \\
\text { um ou mais transtornos psiquiátricos; } 47,7 \% \\
\text { com transtornos em comorbidade. }\end{array}$ \\
\hline $\begin{array}{l}\text { CUNHA, } \\
\text { ROPELATO, } \\
\text { \& ALVES, } \\
2006\end{array}$ & $\begin{array}{l}\text { Apresentar um perfil da idade } \\
\text { com a gravidade de delitos } \\
\text { cometidos por adolescentes } \\
\text { e adultos em unidades } \\
\text { socioeducativas de internação } \\
\text { e instituições prisionais como } \\
\text { motivação para a redução da } \\
\text { maioridade penal. }\end{array}$ & $\begin{array}{l}\text { Adolescentes de } 16-18 \text { apresentaram delitos } \\
\text { de igual gravidade aos adultos pesquisados, } \\
\text { indicando correlação positiva entre idade } \\
\text { e gravidade de delito, ou seja, quanto mais } \\
\text { velhos, maior a gravidade do delito. }\end{array}$ \\
\hline $\begin{array}{l}\text { DELL'AGLIO } \\
\text { et al., } 2005\end{array}$ & $\begin{array}{l}\text { Investigar a ocorrência } \\
\text { de eventos estressores } \\
\text { no desenvolvimento de } \\
\text { adolescentes. }\end{array}$ & $\begin{array}{l}\text { Entre as } 50 \text { adolescentes, identificaram-se } \\
\text { eventos estressores como: maus-tratos, abuso } \\
\text { sexual, uso de drogas, repetência escolar, } \\
\text { desemprego e morte dos pais, que são fatores } \\
\text { de risco ao desenvolvimento. }\end{array}$ \\
\hline $\begin{array}{l}\text { PERES et al, } \\
2002\end{array}$ & $\begin{array}{l}\text { Descrever o perfil de } \\
\text { adolescentes quanto ao apoio } \\
\text { social e familiar, ao uso de } \\
\text { drogas } \\
\text { e os conhecimentos, as } \\
\text { práticas e atitudes relacionadas } \\
\text { à Aids e sua prevenção. }\end{array}$ & $\begin{array}{l}\text { Entre os } 275 \text { adolescentes, } 90 \% \text { residiam } \\
\text { com suas famílias antes da internação; } \\
61 \% \text { haviam abandonado os estudos; } 12 \% \\
\text { haviam usado drogas; e 5,5\% eram usuários } \\
\text { de drogas intravenosas. A maioria }(98 \%) \\
\text { era sexualmente ativa; } 35 \% \text { haviam tido } \\
\text { mais de } 15 \text { parceiras(os) sexuais ao longo } \\
\text { da vida. Muitos afirmaram que adquirir } \\
\text { o HIV “é parte da vida” e que suas vidas } \\
\text { apresentam riscos piores, como sobreviver na } \\
\text { criminalidade. }\end{array}$ \\
\hline
\end{tabular}

A situação de fragilidade dos adolescentes em medidas de internação é flagrante (quadro 2): vivência de violência, uso de drogas, transtornos emocionais e uso da sexualidade sem nenhum cuidado preventivo. Zappe e Ramos (2010) relatam que esses adolescentes buscam prazer e reconhecimento social numa sociedade em que as barreiras às principais modalidades de inserção encontram-se praticamente inacessíveis a muitos deles. Através do ato infracional, o adolescente 
busca essas experiências de prazer, aparentemente contidas nos objetos oferecidos pelo mundo globalizado.

No aspecto drogadição, os resultados encontrados por Martins e Pillon (2008) revelam que os índices do uso do álcool, cigarro e maconha pela primeira vez são elevados e ocorrem concomitantemente, com idade média de 12 anos. Evidenciou-se correlação estatística significativa entre o uso do álcool e da maconha com os atos infracionais, com exceção do homicídio, sugerindo que o uso de drogas precede a prática infracional. Já Zappe e Dias (2012a) destacam que a prática de atos violentos e uso de drogas estão relacionados com estrutura psíquica frágil, comum nos adolescentes.

Huculak et al. (2011) encontraram altas taxas de exposição à violência similares entre meninos e meninas, associando o fácil acesso a armas de fogo e a passagem prévia pela Justiça.

Apenas um artigo sugere a redução da maioridade penal, ao apresentar correlação da idade com a gravidade de delitos cometidos, em estudo realizado em apenas uma unidade socioeducativa do Paraná. Segundo os resultados apresentados na pesquisa, a idade é um fator que varia positivamente em relação à gravidade do delito, ou seja, quanto maior a idade, mais grave o delito (CUNHA et al., 2006).

\section{Representação social do adolescente em conflito com a lei}

As representações sociais são modalidades de conhecimento prático orientadas para a comunicação e para a compreensão do contexto social, material e ideativo (JODELET, 1985). São, consequentemente, formas de conhecimento que se manifestam como elementos cognitivos - imagens, conceitos, categorias, teorias -, mas que não se reduzem aos componentes cognitivos. Socialmente elaboradas e compartilhadas, contribuem para a construção de uma realidade comum, possibilitando a comunicação. São, essencialmente, fenômenos sociais que, mesmo acessados a partir do seu conteúdo cognitivo, precisam ser entendidos a partir do seu contexto de produção.

Cinco artigos abordaram o aspecto das representações sociais dos adolescentes em privação de liberdade, em relação a sua vida e ao contexto social em que estão inseridos, previamente, durante e após a internação (QUADRO 3). 
Njaine e Minayo (2002) investigam o papel da imprensa na produção de uma imagem negativa e incriminadora dos adolescentes em conflito com a lei, pouco abordando os determinantes sociais contribuintes para seu ingresso ao mundo do crime e o papel do Estado na prevenção ao ato infracional.

Souza e Costa (2012) destacam que o processo de significação do adolescente sobre o período encarcerado parece depender do que lhe é oportunizado para a construção de um novo projeto de vida ao sair do sistema. Também afirmam que, ao contrário das demais medidas socioeducativas, as medidas de internação são as únicas que conseguem provocar sentimentos nos adolescentes, seja raiva, revolta ou sentimento de injustiça.

Aspectos considerados importantes fatores de proteção ao desenvolvimento saudável na adolescência, o acesso aos serviços de saúde, ao estudo e ao trabalho está entre os pilares da socioeducação e nos projetos de vida dos adolescentes privados de liberdade. Embora alguns cogitem a possibilidade de retornar ao crime, essa reflexão sobre o porvir os influencia nas escolhas que são feitas, além de contribuir nas "expectativas quanto ao futuro" (ZAPPE; DIAS, 2012b).

No entanto, atuando como principal entrave no processo socioeducativo, o modelo arcaico e coercitivo de atendimento, que é baseado na contenção, na repressão, coerção e na patologização da adolescência e do ato infracional, vem prevalecendo sobre a prática socializadora proposta em legislação (COUTINHO et al., 2011).

Castro \& Guareschi (2008) corroboram esta fala quando afirmam ser presentes na rotina das instituições socioeducativas o isolamento, como forma de punição, e o uso de medicação psiquiátrica, como meio de controle social. Esses procedimentos vão na contramão dos propósitos socioeducativos que justificariam a privação de liberdade e reforçam a percepção negativa deste período por parte dos internos. Em geral, os adolescentes consideram a internação ruim, devido à ausência da liberdade e à ociosidade que provoca. Isso se evidencia pela falta da oferta de atividades educativas, culturais, profissionalizantes e desportivas, comprometidas com seu desenvolvimento e socialização. Apesar disso, o ato infracional é visto pelo adolescente como um ato "fora da lei", pelo qual admite ser penalizado e castigado. O que não altera a percepção de outros significados que a internação possui para esse adolescente, como o de prisão, manicômio, segregação e castigo. 
Examinando o modo como os adolescentes significam suas práticas de vida e se subjetivam a partir dos contextos da família, da justiça e da medida de internação, esses mesmos autores supracitados constataram que a maioria dos adolescentes reproduz o discurso institucional, significando e subjetivando o discurso da mídia, da sociedade contemporânea e do conhecimento. Ressaltam a distância entre os discursos formais dos juízes e a linguagem usual dos adolescentes internos. Apesar da submissão ao papel representado pela figura de autoridade do juiz, os adolescentes afirmaram não compreender o que lhes é dito durante as audiências e que não são escutados e compreendidos pelos juízes, sinalizando o hiato de comunicação existente (CASTRO; GUARESCHI, 2008).

Quadro 3. Artigos sobre representação social envolvendo adolescentes em medida de internação $(\mathrm{N}=5)$

\begin{tabular}{|l|l|l|}
\hline \multicolumn{1}{|c|}{ Autor e ano } & \multicolumn{1}{|c|}{ Objetivo } & \multicolumn{1}{c|}{ Resultados } \\
\hline $\begin{array}{l}\text { ZAPPE e } \\
\text { DIAS, 2012b }\end{array}$ & $\begin{array}{l}\text { Investigar expectativas quanto } \\
\text { ao futuro de adolescentes } \\
\text { em diferentes contextos } \\
\text { institucionais (família - G1; } \\
\text { instituição de proteção - G2; } \\
\text { instituição socioeducativa - } \\
\text { G3), assim como fatores de } \\
\text { risco ao desenvolvimento. }\end{array}$ & $\begin{array}{l}\text { Investigados 945 adolescentes (14 a 19 } \\
\text { anos, de ambos os sexos). Há diferenças } \\
\text { significativas entre adolescentes dos três } \\
\text { contextos com relação às expectativas } \\
\text { quanto ao futuro. G3 e G2 com } \\
\text { maior número de fatores de risco ao } \\
\text { desenvolvimento. }\end{array}$ \\
\hline $\begin{array}{l}\text { SOUZA \& } \\
\text { COSTA, 2012 }\end{array}$ & $\begin{array}{l}\text { Apresentar o significado que } \\
\text { os adolescentes atribuem } \\
\text { à medida socioeducativa } \\
\text { de internação e às medidas } \\
\text { socioeducativas cumpridas } \\
\text { anteriormente à internação. }\end{array}$ & $\begin{array}{l}\text { Medidas significadas como sem } \\
\text { importância para suas vidas, exceto a } \\
\text { internação, por ser a única medida que } \\
\text { consegue provocar "alguma coisa" (raiva, } \\
\text { revolta ou sentimento de injustiça). } \\
\text { Internação vista de modo paradoxal: } \\
\text { restringe a liberdade, mas garante o } \\
\text { mínimo de proteção. }\end{array}$ \\
\hline $\begin{array}{l}\text { COUTINHO, } \\
\text { ESTEVAM \& } \\
\text { ARAÚJO, 2011 }\end{array}$ & $\begin{array}{l}\text { Apreender as representações } \\
\text { sociais dos adolescentes acerca } \\
\text { da prática socioeducativa com } \\
\text { privação de liberdade. }\end{array}$ & $\begin{array}{l}\text { Surgiram sete categorias empíricas: } \\
\text { concepção da prática socioeducativa } \\
\text { de privação de liberdade; descrição da } \\
\text { instituição; imagem dos profissionais; } \\
\text { percepção da imagem de si; experiência } \\
\text { de vida; manifestaçáes biopsicognitivas e } \\
\text { projeto de vida. A prática não socializadora } \\
\text { prevaleceu sobre a socializadora. }\end{array}$ \\
\hline
\end{tabular}

continua... 


\begin{tabular}{|c|c|c|c|}
\hline 6 & Autor e ano & Objetivo & Resultados \\
\hline & $\begin{array}{l}\text { CASTRO \& } \\
\text { GUARESCHI, } \\
2008\end{array}$ & $\begin{array}{l}\text { Examinar o modo como } \\
\text { adolescentes significam suas } \\
\text { práticas de vida e se subjetivam } \\
\text { a partir dos contextos da } \\
\text { família, da justiça e da medida } \\
\text { socioeducativa de internação. }\end{array}$ & $\begin{array}{l}\text { A fala dos adolescentes reproduz, em } \\
\text { grande parte, o discurso das instituições, } \\
\text { dos juízes e dos técnicos que lidam com } \\
\text { eles. }\end{array}$ \\
\hline & $\begin{array}{l}\text { NJAINE \& } \\
\text { MINAYO, } \\
2002\end{array}$ & $\begin{array}{l}\text { Identificar como os } \\
\text { adolescentes infratores são } \\
\text { apresentados à sociedade pela } \\
\text { mídia escrita. }\end{array}$ & $\begin{array}{l}\text { Papel da mídia no fortalecimento da visão } \\
\text { negativa e incriminadora dos adolescentes, } \\
\text { podendo contribuir com ações mais } \\
\text { violentas contra esse grupo. }\end{array}$ \\
\hline
\end{tabular}

\section{Saúde do adolescente em conflito com a lei}

Como um conceito proposto pela Constituição de 1988 e pela Lei Orgânica n. 8.080 de 1990, Saúde seria a resultante de condições de alimentação, habitação, educação, renda, meio ambiente, trabalho, transporte, lazer, emprego, liberdade e acesso ao serviço de saúde. A legislação brasileira garante a todos, sem exceção, o direito à saúde por parte do Estado, bem como condiçôes dignas de vida e de acesso igualitário e universal às ações e serviços de promoção, proteção e recuperação no caso de adoecimento, em todos os seus níveis e em todo o território nacional.

O Quadro 4 apresenta 9 documentos que debatem questôes relacionadas à saúde de adolescentes privados de liberdade. Prevaleceram os estudos que investigavam as condições de saúde mental (ANDRADE et al., 2011; CASTELLANA et al., 2014; BARROS et al., 2013; VILARINS, 2014; SCHMITT et al., 2006; DAVOGLIO et al., 2011), acompanhados de dois sobre a saúde bucal (MACHADO et al., 2010; OLIVEIRA et al., 2015) e um sobre fatores protetivos e de risco (ASSIS; CONSTANTINO, 2005).

Diferentes enfoques são dados aos problemas de saúde mental. Andrade et al. (2011) justificam o cenário de prevalência de transtornos psiquiátricos em adolescentes privados de liberdade ao afirmar ser maior o número de adolescentes internos com transtornos psiquiátricos do que o esperado para a população geral da mesma faixa etária.

Outros autores se preocupam em identificar traços de psicopatia. Castellana et al. (2014), analisando jovens com 18 e mais anos em centro socioeducativo, concluíram existir significativas diferenças de personalidade entre adolescentes 
infratores e não infratores, especificamente no que diz respeito a traços psicopatas. Andrade et al. (2011) encontraram mais psicopatologias entre as meninas que nos meninos, em todas as áreas diagnósticas; os transtornos psiquiátricos mais prevalentes foram: déficit de atenção com hiperatividade, transtorno da conduta, transtorno desafiador opositivo, transtornos de ansiedade, transtorno depressivo, abuso/dependência de drogas ilícitas e abuso/dependência de álcool. $\mathrm{O}$ abuso de álcool aumentou em 2,4 vezes a chance de um adolescente cometer delito violento.

Barros et al. (2013) afirmam ter encontrado forte correlação entre psicopatia e índices biológicos de desapego entre jovens infratores entre 15-21 anos. Schmitt et al. (2006) reforçam que aqueles que cometeram crimes contra a vida apresentaram prevalência de psicopatia maior que outros adolescentes infratores, e que a reincidência criminal foi mais prevalente entre os psicopatas, em comparação com internos que não cometeram crimes contra a vida.

Já Vilarins et al. (2014) criticam o atendimento em saúde mental realizado nas unidades socioeducativas ou na rede externa de saúde, que consiste apenas em farmacologização dos transtornos. Pouco se faz pelo "sujeito" por trás do infrator.

Assis e Constantino (2005), além de apresentar características dos adolescentes, debatem a prevenção primária em saúde como forma de prevenir a violência, atuando ainda sobre fatores de risco e agentes da violência, destacandose intervençôes na gravidez e na infância para famílias em situação de risco, treinamento para os pais, programas de prevenção primária realizados em escolas e intervençôes precoces para adolescentes infratores.

Apesar de também ser considerada preditora de qualidade de vida por parte dos adolescentes privados de liberdade, a saúde bucal destes carece de estudos mais aprofundados. Os dois artigos analisados se referem a adolescentes internos em Minas Gerais. Machado et al. (2010) observaram que, em sua maioria, os 183 indivíduos internos nas três unidades da capital apresentavam-se livres de cárie e doenças periodontais (61,0\%). Já Oliveira et al. (2015), em estudo transversal com 102 adolescentes do interior do estado, observaram mais problemas de higiene oral, má oclusão, no estado periodontal, na fluorose dentária e trauma dental, além de alta prevalência de cáries. Esse contraste que acontece em relação aos resultados observados na capital e interior do Estado de Minas Gerais pode significar que políticas públicas de atenção à saúde da população em estudo não contemplem indistintamente todos os jovens que ingressam no sistema socioeducativo nesse estado. 


\begin{tabular}{|c|c|c|}
\hline Autor e ano & Objetivo & Resultados \\
\hline $\begin{array}{l}\text { OLIVEIRA et al., } \\
2015\end{array}$ & $\begin{array}{l}\text { Avaliar o impacto das condições } \\
\text { de saúde bucal na qualidade de } \\
\text { saúde oral e de vida (QV) de } \\
\text { adolescentes encarcerados do } \\
\text { sexo masculino. }\end{array}$ & $\begin{array}{l}\text { Problemas de saúde bucal exerceram } \\
\text { influência na QV. 64\% dos } \\
\text { adolescentes referiram impacto sobre } \\
\text { a QV; cárie não tratada é principal } \\
\text { preditor da saúde bucal. }\end{array}$ \\
\hline VILARINS, 2014 & $\begin{array}{l}\text { Analisar como são atendidos } \\
\text { os adolescentes com transtorno } \\
\text { mental em cumprimento de } \\
\text { medida socioeducativa de } \\
\text { internação. }\end{array}$ & $\begin{array}{l}\text { Atendimento em saúde mental } \\
\text { realizado na unidade socioeducativa } \\
\text { ou na rede externa de saúde consistiu } \\
\text { em medicalização. }\end{array}$ \\
\hline $\begin{array}{l}\text { CASTELLANA et } \\
\text { al., } 2014\end{array}$ & $\begin{array}{l}\text { Avaliar a presença de traços } \\
\text { de psicopatia primários ou } \\
\text { secundários. }\end{array}$ & $\begin{array}{l}\text { Significativas diferenças de } \\
\text { personalidade, especificamente traços } \\
\text { psicopatas, entre jovens infratores } \\
\text { e não infratores. Necessidade de } \\
\text { intervenções de grande alcance. }\end{array}$ \\
\hline $\begin{array}{l}\text { BARROS et al., } \\
2013\end{array}$ & $\begin{array}{l}\text { Investigar traços de psicopatias } \\
\text { em jovens internados. }\end{array}$ & $\begin{array}{l}\text { Ligação entre níveis de psicopatia e } \\
\text { índices biológicos de desapego. }\end{array}$ \\
\hline $\begin{array}{l}\text { DAVOGLIO et al., } \\
2011\end{array}$ & $\begin{array}{l}\text { Descrever resultados sobre } \\
\text { a investigação de aspectos } \\
\text { interpessoais da psicopatia } \\
\text { mediante a utilização de } \\
\text { escala Medida Interpessoal de } \\
\text { Psicopatia (IM-P). }\end{array}$ & $\begin{array}{l}\text { Resultados demandam cautela } \\
\text { e continuidade da pesquisa no } \\
\text { contexto brasileiro. Concordância } \\
\text { interavaliadores foi consistente. A } \\
\text { escala se mostrou confiável. }\end{array}$ \\
\hline $\begin{array}{l}\text { ANDRADE et al., } \\
2011\end{array}$ & $\begin{array}{l}\text { Avaliar a prevalência de } \\
\text { transtornos mentais em } \\
\text { adolescentes sob medida } \\
\text { socioeducativa, considerando } \\
\text { como hipótese a diferença entre } \\
\text { gêneros com base no tipo de } \\
\text { delito cometido. }\end{array}$ & $\begin{array}{l}\text { Prevalência de transtornos } \\
\text { psiquiátricos é maior que a encontrada } \\
\text { na população geral. Meninas tendem } \\
\text { a ter perfil psicopatológico com mais } \\
\text { transtornos que meninos em todas as } \\
\text { áreas diagnósticas. Mais prevalentes: } \\
\text { déficit de atenção e hiperatividade, } \\
\text { transtorno da conduta, transtorno } \\
\text { desafiador opositivo, transtornos } \\
\text { de ansiedade e depressivos, abuso/ } \\
\text { dependência de drogas ilícitas e de } \\
\text { álcool. Abuso de álcool aumenta a } \\
\text { chance de cometer delito violento. }\end{array}$ \\
\hline $\begin{array}{l}\text { MACHADO, } \\
\text { ABREU \& } \\
\text { VARGAS, } 2010\end{array}$ & $\begin{array}{l}\text { Relacionar a saúde bucal dos } \\
\text { adolescentes com os dados } \\
\text { sociodemográficos. }\end{array}$ & $\begin{array}{l}\text { Adolescentes apresentaram-se, em } \\
\text { sua maioria, livres das doenças cárie e } \\
\text { periodontal }(61,0 \%) .\end{array}$ \\
\hline
\end{tabular}




\begin{tabular}{|l|l|l|}
\hline \multicolumn{1}{|c|}{ Autor e ano } & \multicolumn{1}{c|}{ Objetivo } & \multicolumn{1}{c|}{ Resultados } \\
\hline $\begin{array}{l}\text { SCHMITT et al., } \\
2006\end{array}$ & $\begin{array}{l}\text { Comparar a psicopatia, a } \\
\text { reincidência criminal e a } \\
\text { história de maus-tratos entre } \\
\text { adolescentes infratores. }\end{array}$ & $\begin{array}{l}\text { Adolescentes que cometeram crimes } \\
\text { contra a vida com mais psicopatia } \\
\text { que outros adolescentes infratores. } \\
\text { Reincidência criminal mais prevalente } \\
\text { entre os que possuíam psicopatia } \\
\text { e história de crimes contra a vida. } \\
\text { Sem diferença na história de abuso } \\
\text { na infância entre adolescentes com } \\
\text { psicopatia em comparação ao grupo- } \\
\text { controle de infratores. }\end{array}$ \\
\hline $\begin{array}{l}\text { ASSIS \& } \\
\text { CONSTANTINO, } \\
2005\end{array}$ & $\begin{array}{l}\text { Revisar as principais e atuais } \\
\text { teorias de prevenção à violência } \\
\text { cometida por adolescentes, } \\
\text { debatendo a prevenção primária } \\
\text { em saúde como forma de } \\
\text { prevenir a violência. }\end{array}$ & $\begin{array}{l}\text { Apresenta caracterização dos } \\
\text { adolescentes e destacada atividades } \\
\text { de prevenção em saúde com impacto } \\
\text { na redução da infração juvenil: } \\
\text { intervençóes na gravidez e infância } \\
\text { precoce para famílias em situação } \\
\text { de risco; treinamento para pais; } \\
\text { programas de prevenção primária } \\
\text { realizados em escolas e intervençóes } \\
\text { precoces para adolescentes infratores. }\end{array}$ \\
\hline
\end{tabular}

\section{A família do adolescente em conflito com a lei}

Entendida por Souza e Costa (2013) como um sistema aberto e sempre em transformação, a família é preponderante para a estruturação socioafetiva dos indivíduos em desenvolvimento. As relações estabelecidas na família e na escola podem funcionar como fator protetivo ou de risco, independentemente de classe social ou étnica.

Neste levantamento, a família do adolescente privado de liberdade surge como categoria central de análise em 5 artigos (QUADRO 5). Desses, 2 afirmam que condiçôes familiares desfavoráveis e presença de rede social precária estão associadas à ocorrência de atos infracionais, indicando como o adolescente é afetado e afeta o contexto a que pertence (DIAS et al., 2011; ZAPPE; DIAS, 2012a). Souza e Costa (2013) alertam que a existência de um adolescente em conflito com a lei pode significar que há problemas na família.

Se os determinismos sociais apontam a família como principal responsável pela infração cometida pelo adolescente, também esta sofre as consequências de relações sociais excludentes. Muitas vezes, nos processos judiciais, os pais 
ou cuidadores sofrem, ainda que indiretamente, uma espécie de julgamento moral, sendo responsabilizados por abandono e negligência, associados ao cometimento dos atos infracionais por parte de seus filhos. A maioria das mães dos adolescentes internos se sentem impotentes e solitárias diante da dor de ter um filho privado de liberdade, desautorizadas a falar por si próprias e impedidas de agir (MANSUR; MACHADO, 2014).

Feijó e Assis (2004) e Zappe e Dias (2012b) retratam o fenômeno da infração juvenil como um fenômeno complexo, resultado da interação entre fatores sociopsicológicos, estruturais e individuais: no primeiro nível, sobressai a influência de instituições de controle social, como a família e a escola, podendo influenciar como fator protetivo ou de risco. A família, como primeiro grupo social, seria a instituição capaz de exercer maior controle sobre o jovem (estabelecimento de regras, horários, puniçôes e recompensas).

Apesar de categorizado aqui como um texto pertencente à Representação Social do Adolescente em Conflito com a Lei, o estudo de Castro e Guareschi (2008) reforça a família como referência afetiva extremamente importante para adolescentes privados de liberdade. Contudo, também o desemprego, a violência, abuso de drogas, as privações de toda ordem a que estes estão sujeitos e as separações dos pais são percebidos pelos adolescentes como principais motivos para o distanciamento da família.

Segundo Feijó e Assis (2004), as vulnerabilidades da maioria das famílias dos adolescentes internos no sistema socioeducativo revelam um histórico de agravos à saúde e de violências sofridas por parte desses adolescentes. Uma forma de se explicar o agravamento à saúde e o aumento nos índices de violência e atos infracionais cometidos pode ser o fato de que, especialmente nas camadas sociais de menor poder aquisitivo, observa-se um gradativo enfraquecimento do "lugar do pai” no contexto familiar e na própria constituição psíquica dos filhos. A ausência acaba dificultando a elaboração da identidade social do adolescente. Outro sério fator de risco para que o adolescente entre em conflito com a lei é o fato de que as mães atualmente estão sobrecarregadas. São elas as principais responsáveis por suprir as necessidades econômicas, sociais e afetivas dos filhos, e em decorrência dessa sobrecarga, podem negligenciar a supervisão e proteção da sua prole.

Dias et al. (2011) mencionam que a relação de autoridade na família está alterada em função da redistribuição do poder, o que pode produzir profundas 
alterações no desenvolvimento dos filhos. Esses autores reiteram que a principal problemática dos adolescentes infratores está relacionada à inexistência do "pai", pois, apesar da quebra de vínculos sociais do jovem com a família, a escola, a igreja e demais instituiçōes responsáveis pelo controle social, a figura paterna possibilitaria à criança a vivência do sistema de limites e proibições.

Souza e Costa (2013) verificaram que, na maioria das famílias dos adolescentes internos no sistema socioeducativo, havia histórico de envolvimento com o crime. Praticamente todos pertenciam a uma camada social economicamente desfavorável e residiam em locais de maior vulnerabilidade social, com altos índices de violência e criminalidade. Também se verificou uma série de violências perpetradas e sofridas por esses adolescentes no meio intrafamiliar.

Sobre a efetividade das medidas socioeducativas, Souza e Costa (2013) afirmam que, para as famílias a medida socioeducativa de internação é a única das medidas previstas capaz de promover a proteção de seus filhos e de provocar alguma mudança em suas vidas, pois o peso de perder a liberdade consegue fazer com que os adolescentes reflitam sobre suas práticas.

Quadro 5. Artigos sobre a família de adolescentes em medidas de internação ( $\mathrm{N}=5)$

\begin{tabular}{|l|l|l|}
\hline \multicolumn{1}{|c|}{ Autor e ano } & \multicolumn{1}{|c|}{ Objetivo } & \multicolumn{1}{c|}{ Resultados } \\
\hline $\begin{array}{l}\text { MANSUR \& } \\
\text { MACHADO, }\end{array}$ & $\begin{array}{l}\text { Analisar como concepçóes de } \\
\text { "vítima" são atualizadas nas falas, } \\
\text { ações, sentimentos e pensamentos } \\
\text { de mães de adolescentes } \\
\text { que sofreram violência } \\
\text { quando cumpriam medida } \\
\text { socioeducativa; avaliar como } \\
\text { tais concepçōes contribuem para } \\
\text { engendrar processos de produção } \\
\text { de subjetividades. }\end{array}$ & $\begin{array}{l}\text { Falas e ações oscilaram entre duas } \\
\text { formas de subjetividade antagônicas: a } \\
\text { reprodução de formas individualizadas } \\
\text { de sofrimento e a criação de formas de } \\
\text { organização coletiva para lutar por seus } \\
\text { direitos, questionando a individualização } \\
\text { da violência. }\end{array}$ \\
\hline $\begin{array}{l}\text { SOUZA \& } \\
\text { COSTA, }\end{array}$ & $\begin{array}{l}\text { Apresentar o significado que as } \\
\text { famílias de adolescentes privados } \\
\text { de liberdade atribuem à medida } \\
\text { socioeducativa de internação } \\
\text { e às medidas socioeducativas } \\
\text { cumpridas anteriormente à }\end{array}$ & $\begin{array}{l}\text { A internação, apesar de restringir a } \\
\text { liberdade dos adolescentes, é significada } \\
\text { pelas famílias como a única medida } \\
\text { socioeducativa que consegue garantir a } \\
\text { proteção de seus filhos, em contraponto }\end{array}$ \\
às demais.
\end{tabular}

continua... 


\begin{tabular}{|l|l|l|}
\hline \multicolumn{1}{|c|}{ Autor e ano } & \multicolumn{1}{|c|}{ Objetivo } & \multicolumn{1}{c|}{ Resultados } \\
\hline $\begin{array}{l}\text { ZAPPE \& } \\
\text { DIAS, 2012 }\end{array}$ & $\begin{array}{l}\text { Investigar a relação entre a prática } \\
\text { de atos infracionais e as relaçóes } \\
\text { familiares de adolescentes em } \\
\text { conflito com a lei, buscando } \\
\text { identificar como os adolescentes } \\
\text { percebem e relatam essa situação. }\end{array}$ & $\begin{array}{l}\text { Há presença de diferentes formas de } \\
\text { violência nas trajetórias de vida dos } \\
\text { adolescentes, assim como fragilidades } \\
\text { nas relações familiares desde momentos } \\
\text { precoces do desenvolvimento dos } \\
\text { adolescentes. }\end{array}$ \\
\hline $\begin{array}{l}\text { DIAS, } \\
\text { ARPINI \& }\end{array}$ & $\begin{array}{l}\text { Descrever e compreender como } \\
\text { se estabelecem as relaçôes do } \\
\text { adolescente infrator com sua } \\
\text { família antes, durante e depois } \\
\text { do cumprimento de medida } \\
\text { socioeducativa. }\end{array}$ & $\begin{array}{l}\text { Medida de internação aplicada ao } \\
\text { adolescente foi recebida com muito } \\
\text { sofrimento pelos familiares. Responsáveis } \\
\text { ora indicam que não sabiam da situação } \\
\text { do adolescente, afirmando desconhecer a } \\
\text { rotina dos adolescentes e que essa poderia } \\
\text { levá-los a condição de internação; ora } \\
\text { falam que tinham conhecimento do } \\
\text { comportamento do adolescente, mas não } \\
\text { imaginavam que essa rotina poderia lhes } \\
\text { prejudicar. }\end{array}$ \\
\hline $\begin{array}{l}\text { FEIJÓ \& } \\
\text { ASSIS, 2004 }\end{array}$ & $\begin{array}{l}\text { Levantar vulnerabilidades do } \\
\text { infrator e sua família. }\end{array}$ & $\begin{array}{l}\text { Fragilidade da maioria das famílias, } \\
\text { em condição de pobreza e exclusão } \\
\text { social, isoladas do amparo social. Os } \\
\text { adolescentes e suas famílias sofrem as } \\
\text { consequências emocionais e financeiras } \\
\text { decorrentes da separação dos pais. }\end{array}$ \\
\hline
\end{tabular}

\section{Discussão}

Do total de 42 artigos incluídos neste estudo, um terço foi publicado no período compreendido entre 2012 e 2015. Essa intensificação na produção acadêmica coincide com a Lei no 12.594 , de 18 de janeiro de 2012, que instituiu o Sistema Nacional de Atendimento Socioeducativo (Sinase). Fruto de uma construção coletiva entre as diversas áreas do governo, especialistas na área e representantes de entidades, além de uma série de debates realizados por operadores do Sistema de Garantia de Direitos em todo o País, o Sinase tem também como atribuição a produção de dados e informações que favoreçam a construção e o desenvolvimento de novos planos, políticas, programas e ações para a garantia de direitos a crianças e adolescentes (CONANDA, 2006).

Entre as questôes de saúde mais investigadas, constata-se uma predominância de artigos sobre à saúde mental da população estudada. Vários estudos partem 
inclusive de diagnósticos de saúde mental, que tendem para a psicopatologização

dos adolescentes. Observa-se assim um discurso de psicopatologização da adolescência e do ato infracional, o que contribui para uma terapêutica quase que exclusivamente biomédica, na qual a medicalização utilizada tem caráter de controle social e não de tratamento dos adolescentes atendidos (ANDRADE et al., 2011; CASTELLANA et al., 2014; BARROS et al., 2013; JOST, 2010; VILARINS, 2014; SCHMITT et al., 2006; DAVOGLIO et al., 2011).

Esse resultado corrobora os achados de Minayo et al. (2003), quando, ainda na década de 1980, comentaram que estudos no campo da psiquiatria faziam associação entre psicopatologia e crime (BORGES, 1986), e entre delinquência juvenil e personalidades psicóticas (BUCHER, 1994), talvez visando estabelecer relevância ao caráter biológico sobre questôes que podem ser de caráter social e que revelam a ausência da família e do Estado (CONSTANTINO, 2001).

Há carência de estudos que lancem luz sobre questôes que envolvem, por exemplo, as barreiras de acesso aos serviços de saúde por parte da população em estudo, visto que, tão ou mais importante que identificar as psicopatologias é possibilitar o acesso aos serviços de saúde, seja lá de que ordem for o problema: mental, físico e/ou social.

$\mathrm{O}$ acesso à educação, habitação, segurança, lazer e outras determinantes sociais em saúde depende, essencialmente, do implemento de políticas públicas e ações previstas na legislação.

Ressalta-se a utilização de termos provenientes da língua inglesa, como delinquência, por alguns textos analisados, sem a devida crítica aos conceitos nacionais de ato infracional e em conflito com a lei, preconizados no país. A utilização de palavras como encarceramento (OLIVEIRA et al., 2015) e delinquência (e suas variações) dá-se em geral em artigos com autores internacionais (HUCULAK et al., 2011; MCLENNAN et al., 2008) e nacionais publicados em inglês (CASTELLANA et al., 2014). Mais que uma discussão semântica, percebe-se a tensão entre diferentes visões de descumprimento da lei durante a infância e adolescência que permanecem nas sociedades e que se refletem na academia.

A escassez de estudos sobre a saúde física dos adolescentes privados de liberdade precisa ser destacada: Minayo et al. (2003) informam que essa população costuma ter carência nutricional, doenças sexualmente transmissíveis, problemas de saúde bucal, doenças de pele e dependência de substâncias químicas. 
Observa-se também no acervo uma carência de discussões sobre a divisão e agrupamento desses adolescentes nas unidades de internação (se feita por faixa etária, tipologia da infração ou outros critérios) e da superlotação, aspectos que comprometem a saúde. Também pouco se fala sobre diferenças de gênero no ambiente socioeducativo e sobre o tema da visita íntima, além de outros aspectos que impactam diretamente na saúde da população em estudo.

A maioria dos estudos analisados aponta a prevalência da lógica menorista nas unidades socioeducativas brasileiras. A prevalência desse modelo de tratamento compromete a saúde, a qualidade de vida e o processo de construção de cidadania dos adolescentes inseridos no sistema socioeducativo, além de potencializar a reincidência e a gravidade dos atos infracionais cometidos. Cunha et al. (2006) verificaram forte correlação entre a gravidade do delito cometido com a idade do adolescente interno, o que corrobora a fala de que os modelos pedagógicos de atenção e desenvolvimento de potencialidades destes adolescentes não fazem frente às práticas conservadoras e punitivas das instituiçôes de internação (OLIVEIRA; ASSIS, 1999; MURAD; SILVA, 2001; BRITO, 2003; SARAIVA, 2005; COSTA, 2007).

Vale ressaltar que o Sinase (BRASIL, 2012a), em seu artigo $8^{\circ}$, da seção que trata dos direitos individuais, reforça o direito do adolescente infrator de receber assistência integral à sua saúde, cabendo aos Planos de Atendimento Socioeducativo, obrigatoriamente, prever ações articuladas nas áreas de educação, saúde, assistência social, cultura, capacitação para o trabalho e esporte. Tais princípios não devem ser descumpridos, ainda que mediante a autoria de um ato infracional.

Também a Portaria n. 1.082 da PNAISARI garante que toda unidade socioeducativa deve ter como referência uma equipe de atenção básica, mesmo quando a unidade tiver equipe interna de saúde. A própria Resolução 165/2012 do Ministério da Saúde, em seu art. 20, proíbe a transferência de adolescentes em cumprimento de medida socioeducativa para hospitais de custódia, salvo decisão do juiz criminal competente ou se o adolescente tiver cometido infração penal com mais de 18 anos de idade. $\mathrm{O}$ avanço trazido pelas leis e normas ainda padece de efetiva implementação no cenário nacional (BRASIL, 2012b). 
Após análise dos resultados encontrados na produção científica sobre o tema em questão, pode-se observar que a precária assistência e a promoção da saúde do adolescente cumprindo medidas socioeducativas em privação de liberdade são desafios complexos e multifatoriais, sobretudo pela fragmentação das ações no atendimento socioeducativo. Seja pela dificuldade de articulação da rede de saúde no atendimento ao adolescente institucionalizado e/ou pela persistência da lógica menorista (punitiva, coercitiva) nos estabelecimentos destinados à socioeducação.

Mesmo após 26 anos de ECA, em geral, a produção aqui analisada revela que sensibilizar gestores, técnicos e socioeducadores quanto à saúde de adolescentes privados de liberdade não é tarefa fácil. Há uma distância considerável entre o ideal jurídico da garantia dos direitos conquistados por esses jovens e a realidade dos direitos violados. ${ }^{1}$

\section{Referências}

ANDRADE, R.C.D. et al. Prevalência de transtornos psiquiátricos em jovens infratores na cidade do Rio de Janeiro: estudo de gênero e relação com a gravidade do delito. Ciência \& Saúde Coletiva. Rio de Janeiro, v. 16, n. 4, p. 2179-2188, abr. 2011.

ASSIS, S.G.; CONSTANTINO, P. Perspectivas de prevenção da infração juvenil masculina. Ciência \& Saúde Coletiva. Rio de Janeiro, v. 10, n. 1, p. 81-90, 2005.

BARROS, D.M. et al. Dimensional assessment of psychopathy and its relationship with physiological responses to empathic images in juvenile offenders. Frontiers in Psychiatry, v. 4, article 147, Nov. 2013.

BASTOS, J.G.S.; MARIN, I.K. Adolescentes exibicionistas: a busca de um olhar. Revista Latinoamericana de Psicopatalogia Fundamental. São Paulo, v. 17, n. 2, p. 175-190, jun. 2014. BORGES, R.W. Psicopatologia e delinquência juvenil. Revista da Associação Brasileira de Psiquiatria, v. 8, n. 3, p. 129-132, 1986.

BRASIL. Lei no 8.069, de 13 de julho de 1990. Estatuto da Criança e do Adolescente. Brasília: Diário Oficial da União, 14 de julho de 1990.

. Lei no 12.594, de 18 de janeiro de 2012. Sistema Nacional de Atendimento Socioeducativo - Sinase. Brasília: Diário Oficial da União, 19 de janeiro de 2012a.

Ministério da Saúde. Secretaria de Atenção à Saúde. Departamento de Açôes Programáticas Estratégicas. Política Nacional de Atenção Integral à Saúde de Adolescentes em Conflito com a Lei: Normas e Reflexōes. Brasília: Ministério da Saúde, 2012b. 

. Presidência da República. Secretaria de Direitos Humanos (SDH). Levantamento Anual dos/as Adolescentes em Conflito com a Lei - 2013. Brasília: Secretaria de Direitos Humanos da Presidência da República, 2013.

Presidência da República. Secretaria de Direitos Humanos (SDH). Levantamento Nacional do Atendimento Socioeducativo ao Adolescente em Conflito com a Lei-2011. Brasília: Subsecretaria de Promoção dos Direitos da Criança e do Adolescente. Secretaria de Direitos Humanos, 2011. 36p.

BRITO, L.M.T. Encruzilhadas do sistema socioeducativo. Psicologia Clínica: Revista de Psicologia da Pontifícia Universidade Católica do Rio de Janeiro. Rio de Janeiro, v. 15, n. 1, p. 75-89, 2003.

BUCHER, R; DONEDA, D.; CARMO, R. Acerca da delinquência juvenil e consumo de drogas. Psicologia: teoria e pesquisa, v. 10, n. 2, p. 287-297, 1994.

CASTELLANA, G.B. et al. Psychopathic traits in young offenders vs. non-offenders in similar socioeconomic condition. Revista Brasileira de Psiquiatria, v. 36, n. 3, p. 241-4, 2014. CASTRO, A.L.S.; GUARESCHI, P. Da privação da dignidade social à privação da liberdade individual. Psicologia \& Sociedade, v. 20, n. 2, p. 200-207, 2008.

CIARALlO, C.R.C.A.; ALMEIDA, A.M.O. Conflito entre práticas e leis: a adolescência no processo judicial. Fractal: Revista de Psicologia, v. 21, n. 3, p. 613-630, set./dez. 2009.

COELHO, M. Adolescente em conflito com a lei: um estudo sobre políticas de ressocialização dos adolescentes atendidos na Unidade de Atendimento de Semiliberdade de Taguatinga. 2013. 94f. Monografia (Graduação em Pedagogia) - UAST/DF, Brasília, 2013.

CONANDA. Parâmetros para a formação continuada de atores do sistema de garantia dos direitos da criança e do adolescente. Brasília, 2006.

CONSTANTINO, P. Entre as escolhas e os riscos possiveis: a inserção das jovens infratoras no tráfico de drogas. 2001. 173f. Dissertação (Mestrado em Saúde Pública) - Escola Nacional de Saúde Pública Osvaldo Cruz, Fiocruz, Rio de Janeiro, 2001.

COSTA, C.R.B.S.F. et al. Música e transformação no contexto da medida socioeducativa de internação. Psicologia: ciência e profissão, v. 31, n. 4, p. 840-855, 2011.

COSTA, C.R.B.S.F. Contexto socioeducativo e a promoção de proteção a adolescentes em cumprimento de medida judicial de internação no Amazonas. Rio de Janeiro, 2007. Tese (Doutorado em Saúde Pública) - Escola Nacional de Saúde Pública, Fiocruz, Rio de Janeiro, 2007.

COUTINHO, M P.L. et al. Psicologia em Estudo. Maringá, v. 16, n. 1, p. 101-109, jan./ mar. 2011.

CUNHA, P.I.; ROPELATO, R.; ALVES, M.P. A redução da maioridade penal: questões teóricas e empíricas. Psicologia: ciência e profissão, v. 26, n. 4, p. 646-659, 2006. 
DAVOGLIO, T.R. et al. Medida Interpessoal de Psicopatia (IM-P): estudo preliminar no contexto brasileiro. Trends Psychiatry Psychother, v. 33, n. 3, p. 147-155, 2011.

DIAS, A.C.G.; ARPINI, D.M.; SIMON, B.R. Um olhar sobre a família de jovens que cumprem medidas socioeducativas. Psicologia \& Sociedade, v. 23, n. 3, p. 526-535, 2011.

FEIJÓ, M.C.; ASSIS, S.G. O contexto de exclusão social e de vulnerabilidades de jovens infratores e de suas famílias. Estudos de Psicologia, v. 9, n. 1, p. 1571-1567, 2004.

FEITOSA, J.B.; BOARINI, M.L. The defense of socio-educational internment: Feature of the hygienist principles. Paideia, v. 24, n. 57, p. 125-133, Jan./Apr. 2014.

GURALH, S.A. A liberdade constitucionalmente prevista e sua relação com a medida socioeducativa de internação. Textos \& Contextos. Porto Alegre, v. 11, n. 1, p. 193-203, jan./jul. 2012.

HUCULAK, S.; MCLENNAN, J.D.; BORDIN, I.A. Exposure to violence in incarcerated youth from the city of São Paulo. Revista Brasileira de Psiquiatria. São Paulo, v. 33, n. 3, set. 2011.

JODELET, D. La representación social: fenómenos, concepto y teoría. In: MOSCOVICI, S. (Org.). Psicologia Social. Barcelona: Paidós, 1985, p. 469-494.

JOST, M.C. Fenomenologia das motivaçôes do adolescente em conflito com a lei. Psicologia: teoria e pesquisa, v. 26, n. 1, p. 99-108, jan.-mar. 2010.

LIBERALI, R. Metodologia científica prática: um saber-fazer competente da saúde à educação. 2. ed. rev. e ampl. Florianópolis: Postmix, 2011, 206p.

MACHADO, D.B.; ABREU, M.H.N.G.D.; VARGAS, A.M.D. Situação de saúde bucal de adolescentes internados em unidades socioeducativas de Belo Horizonte, Brasil. Arq. Cent. Estudos. Curso Odontologia Univ. Fed. Minas Gerais, v. 46, n. 3, p. 160-167, 2010.

MALVASI, P.A. Entre a Frieza, o Cálculo e a "Vida Loka": violência e sofrimento no trajeto de um adolescente em cumprimento de medida socioeducativa. Saúde e Sociedade. São Paulo, v. 20, n. 1, p. 156-170, 2011.

MANSUR, T.S.; MACHADO, L.A.D. Problematizando a noção de vítima de violência. Psicologia \& Sociedade, v. 26, n. spe., p. 183-192, 2014.

MARTINS, M.C.; PILLON, S.C. A relação entre a iniciação do uso de drogas e o primeiro ato infracional entre os adolescentes em conflito com a lei. Caderno de Saúde Pública. Rio de Janeiro, v. 24, n. 5, p. 1112-1120, maio 2008.

MATTAR, L.D. Exercício da sexualidade por adolescentes em ambientes de privação de liberdade. Cadernos de Pesquisa, v. 38, n. 133, jan./abr. 2008.

MCLENNAN, J.D. et al. Trafficking among youth in conflict with the law in São Paulo, Brazil. Society Psychiatry and Psychiatric Epidemiology, v. 43, p. 816-823, 2008. 
MENDES, K.D.S.; SILVEIRA, R.C.C.P.; GALVÃO, C.M. Revisão integrativa: método de pesquisa para a incorporação de evidências na saúde e na enfermagem. Texto Contexto Enfermagem, v. 17, n. 4, p. 758-64, 2008.

MINAYO, M.C.S.; SOUZA, E.R. Violência sob o Olhar da Saúde. Rio de Janeiro: Editora Fiocruz, 2003.

MURAD, J.G.P.; SILVA, R.C. O jovem em conflito com a lei: conhecendo e compreendendo o significado de suas trajetórias em instituições e programas de atendimento na cidade de Ribeirão Preto. In: IV SEMINÁRIO DE PESQUISA, 2001, Ribeirão Preto, SP, Universidade de São Paulo. Anais..., 2001, p. 151.

NJAINE, K.; MINAYO, M.C.S. Análise do discurso da imprensa sobre rebeliōes de jovens infratores em regime de privação de liberdade. Ciência \& Saúde Coletiva, v. 7, n. 2, p. 285 $297,2002$.

OLIVEIRA, M.B.; ASSIS, S.G. Os adolescentes infratores no Rio de Janeiro e as instituições que os "ressocializam". A Perpetuação do Descaso. Caderno de Saúde Pública, v. 15, p. 831844, 1999.

OLIVEIRA, D.C. et al. Impact of Oral Health Status on the Oral Health-Related Quality of Life of Brazilian Male Incarcerated Adolescents. Oral Health Prevent Dental, v. 3, n. 5, p. 417-25, 2015.

PERES, C.A. et al. AIDS prevention among incarcerated teenagers, Brazil. Revista de Saúde Pública, v. 36, n. 4 Suppl, p. 76-81, Aug. 2002.

PRIULI, R.M.A.; MORAES, M.S. Adolescents in conflict with the law. Ciência \& Saúde Coletiva, v. 12, n. 5, p. 1185-92, 2007.

RIO DE JANEIRO (Estado). Assembleia Legislativa. Relatório Anual do Mecanismo Estadual de Prevenção e Combate à Tortura do Rio de Janeiro, Rio de Janeiro: ALERJ, 2015.

SARAIVA, J.B.C. Adolescente em conflito com a lei: da indiferença à proteção integral: uma abordagem sobre a responsabilidade penal juvenil. 2. ed. Porto Alegre/RS: Livraria do Advogado, 2005.

SCHMITT, R. et al. A. Personalidade psicopática em uma amostra de adolescentes infratores brasileiros. Revista Psiquiatria Clínica, v. 33, n. 6, p. 297-303, 2006.

SCISLESKI, A.C.C. et al. Medida Socioeducativa de Internação: dos Corpos Dóceis às Vidas Nuas. Psicologia: ciência e profissão, v. 34, n. 3, p. 660-675, 2014.

SENA, C.A.D.; COLARES, V. Comportamentos de risco para a saúde entre adolescentes em conflito com a lei. Caderno de Saúde Pública. Rio de Janeiro, v. 24, n. 10, p. 2314-2322, out. 2008.

SILVA, J.O; RISTUM, M. A violência escolar no contexto de privação de liberdade. Psicologia: ciência e profissão, v. 30, n. 2, p. 232-247, 2010. 
SOUZA, L.A.; COSTA, L.F. A significação das medidas socioeducativas para as famílias

de adolescentes privados de liberdade. Psico-USF, Bragança Paulista. v. 18, n. 2, p. 277-288, maio/ago. 2013.

The meaning of socio-educational measures for young offenders deprived of their freedom. Acta Colombiana de Psicología, v. 15, n. 2, p. 87-97, 2012.

VICENTIN, M.C.G. Corpos em rebelião e o sofrimento-resistência: adolescentes em conflito com a lei. Tempo Social: Revista de Sociologia da USP, v. 23, n. 1, p. 97-113, 2011. VILARINS, N.P.G. Adolescentes com transtorno mental em cumprimento de medida socioeducativa de internação. Ciência \& Saúde Coletiva, v. 19, n. 3, p. 891-898, 2014.

ZAPPE, J.G.; DIAS, A.C.G. Adolescence, violence and drug use: A multiple case study. Adolesc. Saúde. Rio de Janeiro, v. 9, n. 2, p. 30-36, abr./jun. 2012a.

- Violência e fragilidades nas relações familiares: refletindo sobre a situação de adolescentes em conflito com a lei. Estudos de Psicologia, n. 17, v. 3, p. 389-395, set./dez. 2012b. ZAPPE, J.G.; RAMOS, N.V. Perfil de adolescentes privados de liberdade em Santa Maria/ RS. Psicologia e Sociedade, v. 22, n. 2, p. 365-373, 2010.

\section{Nota}

${ }^{1}$ N.T. Arêas Neto elaborou o projeto de pesquisa, levantamento bibliográfico, análise de dados, categorização e redação técnico-científica. P. Constantino e S.G. de Assis realizaram a análise de dados e a redação técnico-científica. 


\section{Bibliographical analysis of health production of adolescents undergoing social-educational measures in freedom deprivation situation}

This research aims to analyze the publication of scientific articles about health of adolescents undergoing socioeducational measures of deprivation of liberty in Rio de Janeiro, Brazil. An integrative systematic review was made in the following databases between 20002015: Scopus (67 articles), Scielo (73), Virtual Library in Health - BVS (50) and Pubmed / Medline (13), totalizing 218 documents. After exclusion of duplicates and documents that do not meet the inclusion criteria, remained 42 documents. These underwent a thematic categorization as follows: description of adolescents in conflict with the law (15 documents); concepts, laws and history of socio-educational measures and institutional actions for adolescents deprived of their liberty (8); health (9); social representation of adolescents in conflict with the law (5); and family relationship (5). A total of 57.1\% of the articles were published between 2010 and 2015, especially in psychology and public health journals, mostly with qualitative methodology and published by researchers from the South and Southeast of Brazil. After analyzing the results, it was found a greater emphasis on mental health's studies, in contrast to an almost total lack of studies on physical health. It can also be observed that poor care and health promotion of the adolescent deprived of freedom are complex and multifactorial challenges, due to the difficulty of the health network coordination in meeting the institutionalized adolescent, or the persistence of punitive logic in institutions for socio-education.

Keywords: health; adolescents; deprivation of liberty. 